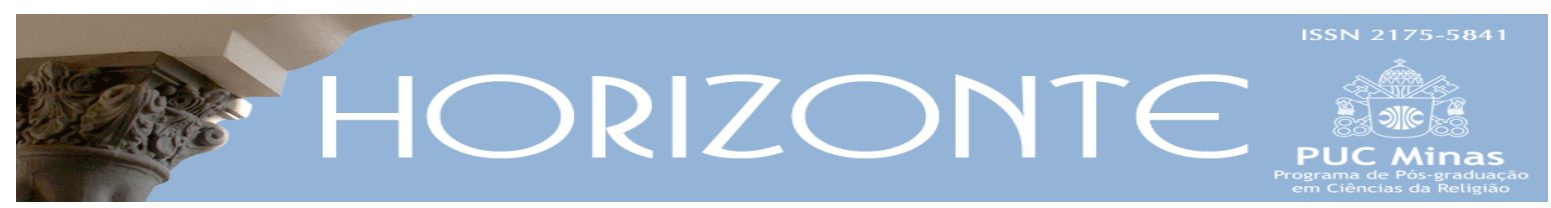

Temática Livre - Artigo Original

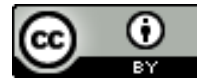

DOI - 10.5752/P.2175-5841.2016v14n42p543

\title{
O tempo messiânico em sua culminância potencial
}

\author{
Messianic time in its potential climax
}

\author{
Adilson Felicio Feiler*
}

\begin{abstract}
Resumo
A temporalidade messiânica introduzida no pensamento de Paulo apresenta uma ruptura no tempo. Mediante o intervalo entre o tempo cronológico e o tempo final - o tempo messiânico - se introduz uma ruptura na ruptura do próprio tempo. Esta ruptura torna a lei estranha e positiva, tal como compreendida por Hegel, em uma lei inoperosa alavancando a operosidade do uso. Logo, um uso operoso equivale a uma crítica à moral e uma ênfase à ação, portanto à ética. Diante disso, torna-se possível uma redenção das críticas de Nietzsche ao Apóstolo Paulo. O Paulo moralista de Nietzsche abre espaço a um Paulo que introduz, no tempo, um espaço onde a vida atinge a sua culminância potencial. Ou seja, viver o tempo do Messias requer a capacidade de ler, nos acontecimentos da vida presente, a atuação incessante do Messias, uma atuação que eleva a vida até a sua plenitude. Viver assim as coisas últimas é viver de modo diferente as coisas penúltimas, tal como São Paulo diz, é viver como se não vivesse.
\end{abstract}

Palavras-chave: Messianismo, lei, moral, ética, tempo.

\begin{abstract}
The messianic temporality introduced in the Paulus thought presents a severance in time. By the interval. between chronological and final time - the messianic time - a severance in the severance of time itself is introduced. Such severance becomes the strange and positive law, as understood by Hegel, in a nonoperate law levering operate of the use. Soon, an operate use amounts a review to moral and an emphasis to action, hence to ethics. In the presence of this, it becomes possible a redemption of the Nietzschean's review to apostle Paulus. The moralist Paulus of Nietzsche opens the space to a Paulus that introduces, in the time, a space where the life catches its potency culmination. That is, living the Messiah's time requires the ability to read, in this life events, the Messiah's relentless performance, a performance that brings life to its fullest. so live the last things is to live differently the penultimate things, as St. Paul says, is living as if he did not live.
\end{abstract}

Keywords: Messianism, Law, Moral, Ethics, Time

Artigo recebido em 17 de novembro de 2015 e aprovado em 21 de junho de 2016.

* Doutor em Filosofia pela PUCRS. Atualmente, é Pós-doutorando pela PUCRS e professor na Universidade do Vale do Rio dos Sinos (Unisinos). País de Origem: Brasil. E-mail: feilersj@yahoo.com.br

Horizonte, Belo Horizonte, v. 14, n. 42, p. 543-556, abr./jun. 2016 - ISSN 2175-5841 


\section{Considerações iniciais}

Através do conceito de pontos culminantes de vida - Lebenshöhepunkte inferimos uma ética, mediante a qual propomos uma reconciliação frente à complexidade do conflito da vida, marcado pelas dimensões normativas e orgânicas. É que, tanto Hegel como Nietzsche, ao apresentarem um novo modo de ser no mundo, marcado pela perda de uma autoridade absoluta e eterna, enaltecem a prática de vida inaugurada com Jesus de Nazaré. "O jovem Hegel tem o Cristo em alta estima" (KUNG, 1973, p.50), assim como "Nietzsche revela simpatias por Jesus" (KUNG, 1976, p.349). Assim, para além de, simplesmente, pensar Hegel como aquele que abre as portas ao ateísmo na modernidade (por conceber a transcendência na imanência), bem como a sua radicalização pela iconoclastia de Nietzsche (por sua luta contra a moral), tal como os nietzschianos pós-modernos até então o tem concebido, em ambos o problema do Cristianismo é uma realidade que provoca, deixando-se afetar pela vivência religiosa cristã, tanto em sua afirmação quanto em seu rechaço, da figura de Jesus.

No nazareno, a reconciliação entre os polos da tensão dialética e a transvaloração dos valores, encontram a culminância pela sua paixão da unidade de todo o existente, que reintegra, em uma unidade superior todas as antinomias, permitindo pensar um novo horizonte messiânico para a humanidade que não se espera acontecer, mas se faz. O acontecer que se depreende do Messianismo da prática de Jesus vive o tempo presente como kairós, e não apenas como espera de um futuro escatológico sem um além redimido, pois no messianismo há sempre a possibilidade de rupturas, como recorda Castor Bartolomé Ruiz (2001) referindose a Walter Benjamin. O Messianismo da prática de Jesus é um Messianismo original, que critica e reconcilia.

Esta dimensão messiânica corresponde à originalidade crística de Jesus, que a história da Igreja Cristã acabou eliminando, como recorda Giorgio Agamben (2006, p.13) em seu O tempo que resta. Comentário à Carta aos Romanos. Neste 
texto, Agamben caracteriza o tempo messiânico como um tempo breve e, por ser breve, é o único tempo restante, o tempo real. Ele o faz a partir das dez primeiras palavras do primeiro versículo da Carta de Paulo: "Paulo escravo do messias Jesus, chamado, enviado, separado para a Boa Notícia de Deus” (Rom, 1,1).

Apresentamos nossa pesquisa em três partes: na primeira trazemos presente a identidade do Messias, que é Jesus, chamado, confrontando-a com a perspectiva hegeliano-nietzschiana da imediatidade, a indeterminidade de todas as determinações; na sequência, apresentamos a práxis do Messias que se dá na diferenciação pela mediação histórica, o Messias que é separado, o que O revela ele como um ser de ação; e, na terceira e última parte, apresentamos a meta do Messias: o envio para a Boa Notícia do Reino que manifesta a sua reconciliação transvalorada. Neste percurso dialético acentuamos a perspectiva do tempo que se depreende da messianidade, que habita uma zona de indeterminação entre o tempo cronológico, o tempo real e o tempo kairótico, o tempo final. Este é um tempo breve, mas um tempo de plenitude; um tempo carregado de potencialidade que reúne uma multiplicidade de rupturas diferenciadas para culminarem no advento da reciprocidade.

\section{A indeterminidade imediata e identitária do Messias}

Jesus, seguindo as reflexões de Hegel em seu escrito da juventude “[...] apareceu não muito antes da última crise que trouxe à tona a fermentação dos múltiplos elementos do destino judaico" (HEGEL, ECD, TWS, 1994, p. 317). Segundo isso, Jesus aparece de maneira imediata, sem se deixar determinar por nenhuma das partes que estão em embate. A vida e ação de Jesus estão desvinculadas dos vários partidos existentes naquele contexto, por essa razão, Jesus se mostra como uma presença livre, indiferente aos padrões determinados.

Ao desenharmos a figura de Jesus no contexto de sua vida pública tomamos, por guia a pintura que Nietzsche faz dele a partir daquela desenhada pelo príncipe 
Michkin, vivida pelo Idiota, de Dostoiévski. Nietzsche tributa a Dostoiévski a sua inspiração como primeiro psicólogo da Europa, não uma psicologia como unidade da alma, mas como pluralidade pulsional, como ciência da subjetividade. Em Dostoiévski e em Nietzsche, nas suas respectivas obras: (O Idiota e O Anticristo) é possível verificar a evolução de seus personagens principais: o príncipe Michkin e Jesus, capazes de se sacrificarem pelo bem de todos. Contudo, embora o Idiota esteja voltado ao bem dos demais, ele não se confunde com eles. A própria denominação de "Idiota” não carrega o significado de "parvo”, "ignorante”, "tolo”, mas aquele, que se mostra livre, aberto e indiferente aos costumes e padrões politicamente estabelecidos. Aquele que é capaz de amar e ter compaixão, mesmo em meio às piores vilezas, "um verdadeiro enviado de Deus" (DOSTOIÉVSKI, IV, 2002, p.41) embora, na aparência, “[...] não passasse de um pobre idiota, quase um pedinte, pronto até a aceitar a caridade alheia"( DOSTOIÉVSKI, V, 2002, p.41). A prática cândida de vida do Idiota se aproxima da prática de Jesus em meio aos abusos farisaicos da lei judaica. Jesus não se apresentou como negador, opositor ou combatente do Judaísmo, mas conservou em tudo o seu si mesmo (JANZ, 1978, p.651), um renunciante, um Idiota. Nietzsche conserva, com isso, uma atitude simpatética para com Jesus, um misto de simpatia e deboche, valorizando o que em Jesus há de mais singular: sua prática. É mediante esta prática que ele elabora a sua ética, uma ética do "Sim", para além de uma vida degenerada pelo Cristianismo dogmático e pela filantropia moderna.

A prática de Jesus é uma prática de neutralidade como recorda Figt (2007, p.335), que não faz diferença entre estrangeiro e nativo, entre judeu e não-judeu (NIETZSCHE, 1969, p.203); uma postura não-doutrinária, não-tendenciosa e cautelosamente comprometida com a crítica de estruturas cristalizadas para a criação do espírito que contribui com a ética do "Sim". A ética do "Sim" não é uma ética da negação da realidade, pois Jesus mesmo é descrito, no Anticristo, como aquele que não pode negar (FIGT, 2007, p.335), mas da "[...] afirmação, como libertação para a totalidade da vida.” (SLOTERDIJK, 2004, p.49) 
Nesta dinâmica messiânica, daquele que, apesar de não se determinar pelas

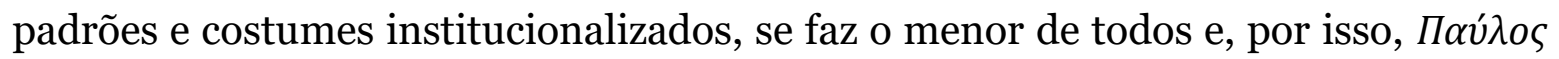
Paulus - sobrenome que significa pequeno, pois ele mesmo se define como o menor de todos, assume a vocação messiânica (Rom 1,1). O tempo messiânico separa o nome de seu portador; nesse tempo o seu nome é apenas impróprio, do tempo messiânico em diante todos os tempos são apenas um sobrenome, são como se não fossem. Isso indica liberdade, isto é, não se deixar determinar pelos padrões e costumes estabelecidos. Por isso, se faz escravo, $\delta o \tilde{v} \lambda o s$. O escravo, em termos jurídicos, é o não-livre; porém, com o evento messiânico, esse termo toma uma nova conotação: a de liberdade. Assim, situado no contexto messiânico, Paulo se

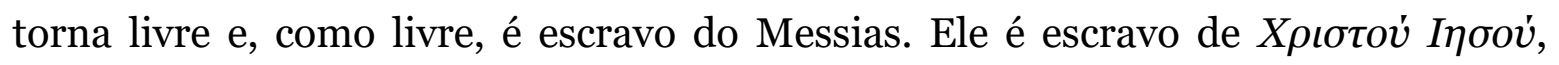
Cristo Jesus; Cristo é o Messias, o ungido, é, pois, um nome próprio.

Ser livre para ser escravo, eis pois um paradoxo que o Apóstolo Paulo inaugura; trata-se, contudo, de ser livre daquilo que leva à escravidão, para ser escravo daquilo que liberta. Jesus se mostra como um ser não resignado, capaz de agir em circunstâncias as mais adversas. Por isso, mais uma vez, o Idiota, como muito bem notou Nietzsche, consegue captar a psicologia de Jesus, aquele que se escraviza para a liberdade e, com isso, é livre, pois a nada se prende: “[...] ele mesmo acima [do destino] procurou elevar o seu povo [sobre este]" (HEGEL, ECD, TWS, 1994, p. 317). Por isso, é apenas na condição da indeterminidade da liberdade que o Messias pode realizar a sua missão, a qual se dá na diferenciação das mediações históricas pela prática.

\section{A determinidade mediata da práxis messiânica}

O Messias em sua imediatidade indeterminada passa a se determinar nas mediações históricas mediante a sua práxis. Na ação, pelo confronto, o Messias vai se determinando. Esse processo de determinar-se se dá a partir de um chamado, que leva a uma separação culminando em um apostolado. 


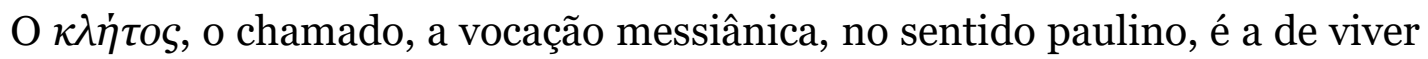
como se não, referente à passagem de 1 Cor 7, 29-32; é a vocação de viver no mundo como se não vivesse. Por isso, viver messianicamente corresponde a viver no mundo ligando-se apenas às coisas a ele pertencentes, apenas pelo uso das mesmas e não pela posse (AGAMBEN, 2006, p. 35). Isso significa fazer das coisas não uma propriedade de seu uso, mas a expropriação na forma de "como se não". A ética fundada no uso, Agamben a recolhe da experiência dos primeiros cristãos que tinham tudo em comum, experiência essa que foi reproduzida, de modo particular, pela vida religiosa em geral, de modo especial a franciscana. O uso faz da propriedade como se não fosse nossa, de modo que a ela apenas nos ligamos pela forma que dela nos utilizamos. A própria lei, neste contexto messiânico, passa de algo estranhamente jurídico para uma praxis pura, de um simples uso. Paulo torna a lei inoperante em seu sentido jurídico para ser aberta a seu uso verdadeiro que confere o sentido de plenitude.

O cristão, chamado a partir do mundo para viver no mesmo como se não vivesse aí, se abandona ao mundo, é indiferente a toda a condição mundana, e assim, livre do mundo, é escravo de Deus. O Messianismo, seguindo as sendas de Benjamin, aparece na forma de "como se". Assim, o niilismo nietzschiano se lê como qualquer “como si”, por isso a superação do niilismo se dá em “como se” está no "como si", daí a importância do artista em Nietzsche; uma estetização do Messianismo. A vida do Idiota de Dostoievski deve marcar como uma exigência, em que a relação entre o que é, o que foi e o que será, acentua a realidade contingencial. Para o Apóstolo Paulo, o Messianismo é uma exigência de redenção do que tem sido, pois é o Messias que vive em mim. É a realização do “como se” não. O evento messiânico é anúncio do Reino, tempo de revocação de toda a humanidade que se liberta de si mesma para permitir o uso (AGAMBEN, 2006, p. 50).

Aquele que anuncia o Reino é o $A \Phi \varpi \rho \iota \sigma \mu \varepsilon v o \varsigma$, é aquele que é escolhido, por isso, separado do resto da humanidade. É como Paulo define a sua vocação. Isso 
quer dizer que, na era messiânica, em que se vive, os muros de separação foram derrubados. Paulo quer dizer que está separado daqueles que provocavam a separação entre judeus e não judeus, e assim inaugura o universalismo. Evoca, com isso, com certa ironia, a sua vocação anterior de fariseu, o separado com relação à Torá. O Messianismo introduz em meio à divisão provocada entre judeus e não judeus, um resto. Este resto supera as diferenças, onde não há mais divisões. O resto refere-se a tudo aquilo que vem após toda a divisão e separação; os eleitos; é aquela porção numérica que sobrevive após a catástrofe; são os que permanecem constantes, o excedente do todo.

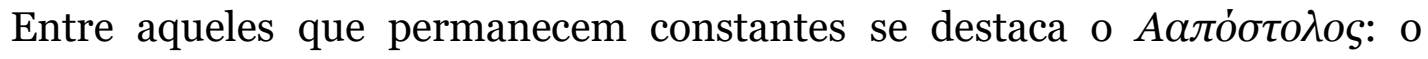
Apóstolo é o enviado, o que realiza o anúncio messiânico. No tempo messiânico o apóstolo ocupa o lugar do profeta. O profeta é aquele que é porta voz imediato de Deus anunciando um tempo que há de vir ainda no presente. A profecia, no tempo escatológico, está reservada para o futuro; o fim dos tempos, o tempo messiânico é o tempo do final, ou seja, o tempo que resta entre o tempo e seu final. E é este tempo messiânico que interessa ao Apóstolo. Portanto, não é nem o tempo cronológico nem o éschaton apocalíptico, mas um resto entre estes dois tempos, que se divide em uma ruptura messiânica (AGAMBEN, 2006, p. 68). O tempo messiânico é uma porção de tempo profano que sofre uma contração que o transforma integralmente; é uma ruptura que divide a divisão em dois tempos e introduz, nela, um resto que excede a divisão (AGAMBEN, 2006, p. 69). O tempo messiânico é o corte do presente entre o passado e o futuro; é um tempo operativo que age desde o interior; é o tempo que temos necessidade para concluir o tempo, por isso é o tempo que resta. É o tempo que resta para o kairós que, por sua vez, é um tempo cronológico abreviado, um tempo operativo que não se distancia muito do tempo profano; é o tempo que se deseja para concluir a representação do tempo. Assim, no evento messiânico há a presença de dois tempos unidos: o chronos e o kairós. O tempo messiânico, em Apóstolo Paulo é um tempo que introduz uma ruptura entre o chronos e o kairós e divide a divisão entre os tempos e introduz um resto, uma zona de indiferenciação (AGAMBEN, 2006, p. 78). O tempo messiânico 
não é nem passado nem futuro, senão a inversão mesma do tempo, o seu cumprimento, a sua plenitude; a recapitulação sumária de todo o passado e futuro no presente, em que cada instante do passado e do futuro é compreendido em sua plenitude do presente. Nesta plenitude se constitui o "[...] ser [é] a síntese do sujeito e do objeto, no qual sujeito e objeto perderam sua contraposição” (HEGEL, ECD, TWS, 1994, p. 326). O tempo messiânico, enfim, é uma articulação de diferenças tal como na rima de uma poesia.

Assim, o determinar-se de Jesus, pelo chamado, faz parte do mundo, embora ainda como se não fosse. A sua determinação não sucumbe ao turbilhão das vicissitudes do mundo, fazendo do uso das coisas do mesmo, a sua posse. Pela separação a determinação d'Ele se constitui na destruição de toda a separação e inauguração do universalismo. E, pelo apostolado, a sua determinação faz do tempo que resta, o tempo presente, o tempo de plenitude. Este é um tempo que resta para concluir o tempo; é um tempo operativo, portanto que abre para o porvir, o destino. Neste tempo o espírito do Cristianismo, a prática cristã atinge a sua culminância. Paulo, por isso, introduz no tempo messiânico uma divisão que rompe com a divisão entre tempo cronológico e tempo kairótico fazendo com que na ênfase da operosidade deste tempo em plenitude os estranhamentos da lei e da moral que se foram apegando ao Cristianismo sejam superados e se recupere o seu espírito. $\mathrm{O}$ “[...] [espírito] que somente é o agente que liga sua palavra e uma ação [...] a conexão da palavra e da ação precisa ser viva, repousar no ser humano mesmo" (HEGEL, ECD, TWS, 1994, p. 330). Palavra e ação constituem um todo; é o espírito do Cristianismo. Diante disso, é possível redimir Paulo das críticas a ele endereçadas por Nietzsche. Pois, segundo este último “[...] Paulo, com aquela insolência rabínica que permeia todos seus atos, deu um caráter lógico a essa concepção indecente deste modo: "Se Cristo não ressuscitou de entre os mortos, então é vã toda a nossa fé" - E de súbito converteu o Evangelho na mais desprezível e irrealizável das promessas, a petulante doutrina da imortalidade do indivíduo" (NIETZSCHE, AC, § 41, KSA, 1969, p. 212-13). No fundo, Paulo está dando um caráter de plenitude ao tempo do Messias, que é já o tempo presente, aquele em 
que palavra e ato constituem um todo, o seu espírito, o que parece ter escapado à compreensão de Nietzsche, que vê na pregação de sua Boa Nova nada senão uma “má nova”(NIETZSCHE, 1969, p.213), o instinto de ódio e vingança. Como se Paulo estivesse, com isso, ressuscitando o instinto do sacerdote judeu que nega a vida e tudo aquilo que é forte para exaltar as coisas vis e desprezíveis do mundo (NIETZSCHE, AC, $\S 45$, KSA, p. 221, 1969) ${ }^{1}$ em nome da moral, quando, na verdade, o que Paulo faz é exatamente o contrário. O tempo messiânico que ele exalta é o tempo que torna inoperante a lei para tornar operante a ação, enfatizando Jesus como homem de ação. Embora Nietzsche reconheça em Jesus aquele que tem atingido o estágio de superação da dor mediante a suspensão da vontade, este heroísmo, acentuado por Nietzsche, não denota a grandeza humana que Jesus põe sobre a ação. Mas, dando um passo além, vamos mostrar que a determinação, da qual resultou a ação, promove reconciliação, superando todas as divisões, transvalorando-as.

\section{A reconciliação transvalorada e o Reino messiânico}

A meta messiânica é a de anunciar o Reino, figura de sua reconciliação. A imagem do Reino carrega a imediatidade indeterminada do Messias e que se foi determinando pela sua práxis nas mediações históricas, para se reconciliar na proposta de sua Boa Nova. Porém, ao mesmo tempo que o Reino reconcilia os momentos anteriores também transvalora, ou seja, não se cristaliza numa proposta moral pétrea, mas se abre para atingir momentos sempre mais culminantes de valores que se prestam a afirmar a vida. A culminância potencial da vida se realiza naquela temporalidade que resta entre o tempo cronológico e o tempo kairótico, uma temporalidade messiânica de plenitude. O tempo messiânico introduz a diversidade de rupturas responsáveis pelo açambarcar da totalidade em plenitude, da qual nada escapa. Nele a plenitude de vida se realiza pelo eterno retorno de epiciclos que reconciliam a parte e o todo, a ruptura e a continuidade na proposta

\footnotetext{
${ }^{1}$ Nietzsche comenta I Coríntios 20-31, dizendo que Paulo exalta o fraco e desprezível para rebaixar aquele que é sábio e forte (Cf. NIETZSCHE, AC, § 45, KSA, p. 221, 1969).
} 
da Boa Nova do Reino.

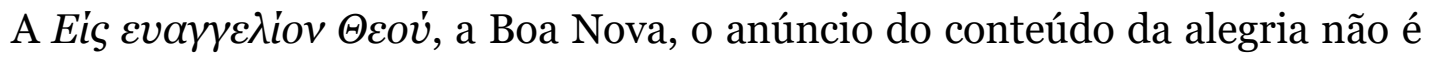
o anúncio de algo futuro, mas presente. É a enérgea do anúncio, o ato enquanto se faz, a unidade entre promessa e realização. Para tanto é preciso exercitar-se na fé que torna inoperante a lei. A lei messiânica torna inoperativa a lei normativa que cristaliza e torna tudo estagnado. O Messias torna inoperante o nomos, pois o Messias é o telos que operacionaliza o ethos. Ele realiza uma aufheben, supera e guarda (AGAMBEN, 2006, p. 100) [...] na abolição precedente da lei desapareceu, através das virtudes, apenas a forma da lei, seu conteúdo permaneceu" (HEGEL, ECD, TWS, 1994, p. 338). Forma-se um estado de exceção sob a forma de suspensão. Para além da lei se introduz um resto: os não judeus; a fé desativa e conserva a lei através do amor. Através da lei no tempo messiânico, pela fé, se coloca novamente o uso. Se o Messias torna a lei inoperante, então uma promulgação da lei com pretensões messiânicas só pode ser o evento do AntiCristo, a maldição do Cristianismo, tal como Nietzsche pensou com a relação entre Cristianismo e Império Romano (NIETZSCHE, AC, § 58, 1969, p. 243). Mais uma vez reafirmamos a redenção de Paulo frente às críticas de Nietzsche. A temporalidade messiânica, em Paulo, entre o cronos e o kairós é a temporalidade que torna inoperosa a lei estranha e que moraliza, para tornar operoso o uso que se faz da lei, abrindo-se uma proposta de ação, uma proposta ética para além de uma proposta moral.

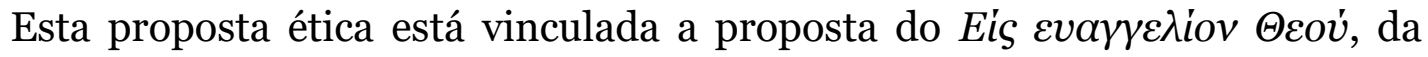
Boa Nova do Evangelho de Deus, e, diante desta, a fé se mostra como um gesto de confiança em pôr a potência de crer em ser de quem se espera proteção. A fé se funda na esfera do direito, possuindo uma dimensão jurídica e uma aliança que implica em um juramento e em um pacto. Nesta perspectiva, o Messianismo é concebido como uma luta interna no âmbito de direito, entre a fé e a lei. Para Paulo a graça completa o âmbito da justiça e da lei. O Messianismo torna inoperante a lei mosaica. A fé que conta para Paulo não deriva da vida de Jesus, mas em sua paixão 
e ressurreição, eis o conteúdo da fé. A fé é uma experiência da palavra e, por isso, que as obras estão associadas à fé. É o ato mesmo de dizer o que se acredita que vale e não em crer em algo do Messias. Esse ato de fé é uma potência que atinge o seu cumprimento na debilidade. Assim, o testemunho da fé expresso na palavra, o ato mesmo da fé está sempre ligado ao uso: o uso da palavra.

O uso, além do mais, abre para uma perspectiva assentada não na posse que cristaliza e torna inoperante a ação, mas que, ao tornar inoperante a lei, torna operoso o uso que dela se faz para o agir, fundando assim uma proposta ética para além da moral. Essa ética prepara a vinda do Messias, isto é, o vir do Messias está no presente (erchetai), aquele que vem, que não cessa de vir. Segundo Benjamim “[...] o Messias consuma todo o suceder histórico no sentido precisamente de criar, redimir, consumar sua relação para com o messiânico.” (BENJAMIN, 2012, p. 01) O tempo messiânico não pode ser confundido com o tempo apocalíptico, que se situa no último dia (parusia). O Messianismo não é o fim dos tempos, mas o tempo do fim, é a relação de cada instante, de cada kairós, é o tempo que se contrai e começa a acabar, o tempo que resta entre o tempo e o seu fim. O tempo messiânico se situa entre os dois tempos judaicos: o "olam hazzeh", o tempo que vai da criação até o fim, e o "alam habba”, que vem depois do fim do mundo. É esse tempo, o messiânico que Paulo chama de "tempo da ressurreição". Este é um tempo que pulsa dentro do tempo cronológico, o que o trabalha e o transforma desde dentro; é o tempo que nos liberta da representação ordinária do tempo; é uma experiência nova do tempo. É o tempo operativo (Kairós), o único tempo que temos, e fazer a experiência desse tempo é transformar-nos integralmente em nosso modo de viver (1Cor 7, 29-31). Este é o tempo da re-vocação de toda a vocação, que muda e esvazia a partir de dentro toda a experiência e toda a vocação factual para abri-la para um novo uso. O tempo messiânico é uma transformação do tempo cronológico. Viver assim as coisas últimas é viver de modo diferente as coisas penúltimas, tal como São Paulo diz: "Viver neste mundo como se não vivesse" (1Cor 7, 31). A escatologia é, pois, a transformação da experiência das coisas penúltimas. A realidade última des-ativa, des-opera, suspende e transforma a realidade penúltima. É o que 
acontece no interior deste tempo, o tempo do Messias, o tempo do agora (2Cor). Viver o tempo do Messias requer a capacidade de ler, nos acontecimentos da vida presente, a atuação incessante do Messias, uma atuação que eleva a vida até a sua culminância potencial.

\section{Considerações Finais}

A atualidade do tempo messiânico está ligada à recapitulação abreviada da história da humanidade. O tempo messiânico em Paulo sempre traz a correspondência entre o tempo e o agora. É, pois, um tempo de plenitude em que tudo é nele recapitulado e reconciliado: a sua identidade indeterminada e a sua práxis determinada, a lei e a graça, a posse e o uso. E é só nesse tempo que a culminância potencial da vida pode se efetuar ao conduzir a potencialidade imediata da nossa ação a abrir-se e determinar-se pela sua diversidade de perspectivas para reconciliar-se na reciprocidade do uso.

A identidade messiânica, que embora imediata e indeterminada, é o fundamento pela qual o Messias vai se constituindo. Pois é graças ao fato de ele não vir já determinado que é capaz de ser o instaurador de uma ética, caso contrário seria nada mais que um propugnador daquela moral judaica existente. Como Hegel se expressa, Jesus aparece logo após a última crise, isso quer dizer que não vem provocar a crise, pois esta já está instalada. O que ocorre é que Ele, tal como o Idiota de Dostoiévski, em meio a toda a crise, se mostra como aquele que não se deixa determinar por ela, porque é livre perante a mesma. A liberdade messiânica é o que permite que ele passe desta indeterminidade a um estado de determinidade pela sua constante diferenciação em meio às mediações históricas. Pelo constante confrontar-se, o Messias mostra a riqueza das diferenças, da diversidade. As marcas da diferença são basicamente as rupturas, vividas no ínterim entre o tempo cronológico e o tempo kairótico, entre o início e o fim. Este é o tempo que abre para a inoperosidade da lei e da moral abrindo para a operosidade do uso. Este espaço do uso é o espaço da reconciliação, aquele que faz emergir a proposta da Boa Nova 
do Reino, que açambarca a totalidade do existente. Nesta, a vida atinge sua culminância potencial, pelo fato de que a temporalidade messiânica torna inoperante a lei, abrindo a possibilidade para a operosidade do uso, portanto da ação.

A proposta ética que emerge do espaço inaugurado pelo tempo messiânico nos conduz a rever a crítica de Nietzsche a Paulo. Desse modo, diferentemente do que pensava Nietzsche, Paulo, ao inaugurar esse tempo messiânico, o tempo de rupturas, abre para a operosidade do uso, da ação, da práxis que desonera a lei e a moral. Portanto, Paulo mostra-se como um crítico da moral e instigador de um ética fundada não na posse que escraviza, mas no uso que liberta.

\section{REFERÊNCIAS}

AGAMBEN, Giorgio. O reino e a glória. São Paulo: Boitempo Editoral, 2007. (Coleção Estado de Sítio).

AGAMBEN, Giorgio. El tiempo que resta. Comentario a la Carta a los Romanos. Madrid: Editorial Trotta, 2006. (Coleção Estructuras y Procesos).

BENJAMIN, Walter. Fragmento Político-teológico. In: BENJAMIN, Walter. O anjo da história. Belo Horizonte: Autêntica Editora, 2012.

DOSTOIEVSKI, Fiódor. O idiota. São Paulo: Editorial 34, 2002.

FIGL, Johann. Nietzsche und die Religionen: trankulturelle perspectiven seines bildungs- und Denkweges. Berlim: Walter de Gruyter, 2007.

HEGEL, G. W. F. Der Geist des Christentums und sein Schicksal (1798/180o): Der Geist des Judentums, Der Geist des Christentums. In: HEGEL, G. W. F. Frühe Schriften. Frankfurt: Suhrkamp Taschenbuch, 1994. Werk 1, p. 317-418. (Suhrkamp Taschenbuch Wissenschaft, 601).

HEGEL, G. W. F. O Espírito do Cristianismo e seu destino. Revista de Opinião Filosófica, n. 2, v.1, Porto Alegre: EdiPUCRS, jul/dez. de 2010 (por nós traduzida).

JANZ, Curt Paul. Friedrich Nietzsche. Biographie. München: Carl Hansen Verlag, 1978. Bd. 4.

KÜNG, Hans. Incarnation de Dieu: introduction à la pensée théologique de Hegel commo prolégomènes à une christologie future. Bar-le-Duc (Meuse): Desclée de Brouwer, 1973. 
NIETZSCHE, F. W. Der Antichrist. In: COLLI, Giorgio; MONTINARI, Mazzino (Herausgeber). Kritische Studienausgabe. Sechste Abteilung. Dritter Band. Berlin: Walter de Gruyter, 1969.

NIETZSCHE, F. W. O Anticristo, maldição do cristianismo e Ditirambos de Dionísio. São Paulo: Companhia das Letras, 2007.

NIETZSCHE, F. W. Assim falou Zaratustra. Rio de Janeiro: Civilização Brasileira, 1998.

RUIZ, Castor Bartolomé. A exceção jurídica e a vida humana. Cruzamentos e rupturas entre C. Schmitt e W. Benjamin. Revista do Instituto Humanitas Unisinos, São Leopoldo, ano XI, n. 374, set. 2011. Disponível em:

<http://www.ihuonline.unisinos.br/index.php?option=com_content\&view=article\&id=4098\&se cao $=374>$. Acesso em: 22 out. 2013 .

SLOTERDIJK, Peter. O quinto "Evangelho"de Nietzsche. Rio de Janeiro: Tempo Brasileiro, 2004. 